\title{
NeO-STOICISM AND What It Can Do
}

\author{
DANIEL DRUCKER \\ University of Michigan, Ann Arbor
}

\begin{abstract}
ALL hard neo-Stoicism about attitudes of type $M$ the view that no attitude of type $M$ is rationally permitted. Call soft neo-Stoicism about $M$ the view that no attitude of type $M$ is rationally required. Slightly more precisely:
\end{abstract}

Soft Neo-Stoicism aвout $M . \forall S$ : whatever $S$ 's total evidence, $S$ is not rationally required to be in any (disjunction of) $M$-type state(s). ${ }^{1}$

For example, no matter how much evidence I have that someone is a bad person, according to soft neo-Stoicism about hatred, I am not rationally required to hate them. I will defend a moderately qualified version of soft neo-Stoicism about every attitude except full or partial belief, preference, and what, following Lewis (1988), I will call cool attitudes. This view has interesting consequences for issues surrounding so-called 'subjective' properties like 'tasty', and for the scope of REFLECTION-like principles: it shows why REFLECTION-like principles fail for most attitudes, belief included. And, since the rationality of beliefs involving these properties often depends strongly on what non-doxastic attitudes one has, my thesis, though not itself about belief, places strong limits on what beliefs we are rationally required to have.

Contact: Daniel Drucker <druckerd@umich.edu>

1. So there are two ways in which soft neo-Stoicism differs from Whites 2005 nearby view, permissivism about $M$. That view says, roughly, that there are some agents with fixed total evidence who are rationally permitted to respond with either of at least two mutually incompatible states, $m_{1}$ and $m_{2}$, e.g., belief in $p$ and suspension of judgment in $p$. But it might be that the agent must either be in $m_{1}$ or in $m_{2}$. Permissivism allows that even in permissive cases, it can happen that some disjunction of such states is rationally required. Soft neo-Stoicism denies this. Second, permissivism is existentially quantified: there are some permissive cases. Soft neo-Stoicism is universally quanitified: no M-type states or disjunctions of such states are rationally required. 
Before getting to the argument, I want to make a terminological stipulation. Some philosophers use 'rational' in a narrow sense, to do only with structural features of combinations of attitudes. ${ }^{2}$ I'm using it in the wider sense familiar from epistemology when people ask, e.g., whether there is a unique rational response to a given body of evidence. ${ }^{3}$ This use isn't local to epistemology, since we also evaluate the rationality of emotional responses to situations. It's rational to be angry at someone for stealing your car, and it's rational for an interested novice at chess to admire Bobby Fischer's skill at chess. It's irrational to be angry at someone for borrowing a pen, and it's probably irrational for an interested novice to admire my skill at chess.

This irrationality does not reduce to inconsistency in belief. Even on a view like Nussbaum's (2004), where emotions are evaluative beliefs, one need not have any beliefs that are inconsistent with my anger at your borrowing my pen. For example, the person does not have to think that someone's borrowing their pen is insignificant in order for their anger to be irrational. This is similar to the epistemic: if after seeing a large number of white swans, and no non-white swans, I end up with a lower credence that the next swan will be white, I am irrational, even if my beliefs are consistent.

The sense of 'rational' I'm after does not mean 'practically successful', either. A person might have great responses to their evidential situation but be punished for their accuracy, as in an anti-scientific community. Their beliefs are not irrational. Similarly, imagine a parent overwhelmed by grief for their dead child. They would succeed at more of their projects if they never felt the grief, or felt it for a very short time, but the attitude is not irrational.

Helpful here is the evaluative sense of 'makes sense'. When we say that a response "makes sense", we offer a kind of approval of the response; we don't just understand how a response occurred, but how it was appropriate, even if that response would not be our own. A response to evidence, or a feeling, is rational when it makes sense. ${ }^{4}$ So, $S$ is rationally required to $\varphi$ in $C$ just when, if $S$ were not to $\varphi$ in $C, S$ wouldn't make sense at least in part in virtue of $S$ 's not $\varphi$-ing. I'll delve more deeply into this conception in Section 2, when I explain why soft neo-Stoicism is true for the target types of attitudes.

\section{The Simple Argument}

My strategy for arguing for soft neo-Stoicism will be, first, to present a very simple and intuitive argument for it, and then to show that the thesis can do a lot of philosophical work, too. But the simple argument is too simple; it will

2. See, e.g., Scanlon (1998), Reisner (2013), and Worsnip (in press).

3. See Greco and Hedden (in press) for discussion.

4. For this usage, see Gibbard (1990). 
have to be modified in various ways, which will then give us the qualified neoStoicism that I prefer.

Imagine a dedicated Stoic, or at least a caricature of a dedicated Stoic. After reading Seneca, Epictetus, Aurelius, and others, she decides that emotions are one of the main causes of misfortune, and that life would go better for each of us if we were to discard them. She might think, for example, that it is because of anger or hatred that we are able to do harm to others knowingly and intentionally. One by one, she sees, or thinks she sees, good reasons to eliminate this or that emotional response. And, through strict training, she eventually comes to live a life without, or mostly without, emotion. ${ }^{5}$ This might not be possible for a human, but I'll ignore that for now. My big claim is that, whatever criticism we make of the Stoic's rejection of emotions, it will not be that she is irrational. She might be cold, callous, or dull, but $s$ ! he is not violating any rational requirements. In fact, she seems like a certain kind of paragon of rationality-if it helps, imagine an extreme version of Spock.

So, there are no circumstances she can be in where the rationally required response is to have a certain emotion. But nothing in particular was said about her circumstances-she might be in any, compatible with her thinking she ought to discard her emotions. So, there are no circumstances that rationally require a particular emotional response of her. Moreover, the Stoic isn't special; what is rationally required of her is just what is rationally required of anyone. So, no one faces any circumstances where an emotional response is rationally required. That is, soft neo-Stoicism about the emotions is true.

As a matter of fact, the Stoics avoided emotion. But they might have avoided other kinds of mental state, too. They might have avoided a kind of sensorial attachment to the world. For example, they might have tried avoiding being discriminating about taste, finding some things tasty. Similarly, they might have avoided being disgusted by things. In fact, they might have tried to avoid all kinds of affective attachment to the world, though, again, it is doubtful that any human could succeed in this. Suppose they did, or, more realistically, suppose some succeed at affective detachment for some things, and others for others, covering all possible modes of affective detachment. Again, it doesn't seem like any just criticism will involve charges of irrationality. They are missing out on something, perhaps, but they are not irrational. Following the reasoning from above, soft neo-Stoicism about all varieties of affective engagement is true.

Of course, there are some attitudes it would be irrational for a Stoic not to have. The Stoic will still act, at least in a broad sense of 'act'. So she needs the minimal apparatus for intelligent action. That is, she needs at least some mental states that are the minimal components of good decision-making. This

5. This will be qualified in a moment; really the Stoic comes to live without warm emotions, because she can still act. 
will at least involve some doxastic states and some desiderative states. They might be full belief and desire, as a kind of neo-Humeanism might have it. Or they might be credences and preferences, as orthodox decision theory would require. We might also expect that other, separate attitudes are required, for example intention. ${ }^{6}$

Wouldn't the Stoic want to avoid desire, though? Desire is, after all, of a piece with the emotions in certain respects, for example in its ability to distract us. In a sense, this is right, and the Stoic might try to avoid desire, but only a certain kind. Take Lewis's (1988) case of Meane and Neiss. In the story, the latter is your friend, who, while good at philosophy in areas your department requires, is less good than Meane, who's a bit of a jerk. You don't want to vote for Meane instead of Neiss as a new hire in your department, but you do vote for them-or, better, as Lewis says, you have no warm desire to vote for Meane, but you really do still want to. ${ }^{7}$ Cool desires, as I understand them, are those mental states that are not warm that combine with beliefs (in the way characteristic of desires) to form actions, regardless of whether they have a particular feel. Warm desires, by contrast, are phenomenologically rich, and are only a subset of the desires that guide our action. Another way of putting that is that we wou! ld still have the desires necessary to produce action if we had no warm desires. But a person couldn't act without some desires. So, again by the same reasoning as before, if some desires are rationally required, they will be cool desires.

We can make the warm/cool distinction with other mental states, too. Take fear. Consider what sort of attitude the following expresses:

(1) I'm afraid that a Republican will win the 2016 Presidential election.

Most people who sincerely say (1) won't have sweaty palms or racing pulses, or their phenomenological concomitants. This contrasts with the following:

\section{(2) I'm terrified of that spider over there.}

The attitude expressed by (1) seems to have to do with the expectation (not necessarily propositionally articulated) of a significant loss of utility compared with possible alternatives. That seems to be the core of the two kinds of fear. Compare, e.g., Aristotle's definition of 'fear' ['phobos']: "some pain or disturbance caused by a representation [phantasia] of a future painful or destructive evil". 8 That seems clearly to be targeted at warm fear.

I said the Stoic will have types of attitudes she has to have to make intelligent choices in decision problems. Probably that includes credences, preferences, and

6. See, e.g., Bratman (2000).

7. Schiffer (1976) gives a related distinction between desires that provide reasons to $\varphi$ and desires that respond to reasons to $\varphi$. I use Lewis's distinction, though Schiffer's is also relevant.

8. Rhetoric, Bk. II, Ch. V. The translation is my own. 
intentions. ${ }^{9}$ As I'll use the term, a cool attitude-type will be any attitude-type that reduces to combinations! of attitude-types necessary for intelligent choice. On this view, cool fear might get to count because it can be analyzed as something like: significant credence that $p$, where $p^{\prime}$ s truth has significant disutility for the fearer. Cool hope will be the reverse: significant credence that $p$, where $p^{\prime}$ s truth has significant utility for the hoper.

This leads to the question: will every attitude-type have cool variants? ${ }^{10}$ Here's a reason to think so: cool anger that $p$, e.g., might be the belief that $p$ obtains because of unjust circumstances, accompanied by the (cool) preference that $p$ not obtain. I don't want to rule this out, though English seems equivocal. (Is there really cool outrage?) Instead, I want to say why that wouldn't be a problem for my account, even if true.

Distinguish between object-neutral and object-specific attitude-types. The former are specifiable without specifying any object, or, for propositional attitudetypes, contents of those attitudes. So preference, credence .5, and (warm) hope would all count. Object-specific attitude-types require giving some specific contents: belief that something is unjust, say, or a particular preference for $p$ over $\neg p$. The analyses I gave of cool fear, cool hope, and cool anger all involve varying degrees of object-specificity. Whether or not any one of these is ever rationally required will turn on whether the specific preferences are rationally required, or the specific beliefs. As I've described her, the neo-Stoic will have preferences and beliefs, since she needs to act, but I never said anything specific about which preferences or beliefs she has to have. Perhaps, following Hume (1975), no specific preferences are rationally required. But I d! on't need that strong claim. For my purposes, it's enough that we can't infer that a cool attitude-type can be rationally required just from its coolness-we'll often need to dig into the details. Specific cool attitude-types might or might not sometimes be rationally required. ${ }^{11}$

9. Are credences necessary? Perhaps we only need full beliefs in probabilities. I won't take a stand on this issue, but on the most well-worked out discussion of the issue to date, Moss (in press Chapter 1), credences go together with full beliefs in probabilities. The problem has a general form: suppose having one of $M_{1}$ and $M_{2}$ is necessary for intelligent decision-making, but neither $M_{1}$ nor $M_{2}$ is individually necessary. Though I doubt this is the actual situation, if it were, I could nevertheless define 'cool' inductively: either credence (or belief), preference (or desire), intention, or any attitude built out of them (and attitudes built out of them, etc.).

10. I want to thank an anonymous referee for raising this issue.

11. Here's a related objection involving cool attitude-types. (Thanks again to an anonymous referee.) Suppose, as is certainly possible, cool and warm attitude-types are simply different ways of experiencing the underlying emotions, and that $S$ is rationally required to have fear. Then $S$ is rationally required to have warm or cool fear. Suppose that $S$ is unable to have cool fear. Then, by some 'ought'-implies-'can' principle, $S$ is rationally required to have warm fear, i.e., soft neo-Stoicism is false. I have a couple responses. First, in Section 4, I reject the relevant 'ought'-implies-'can' principles. Second, it isn't obvious that it's possible for warm fear to be 
So, the argument I gave for soft neo-Stoicism doesn't apply to belief (or credence), cool desire (or preference), or the other cool mental states. As I suggested, the divide seems to be this. There are some mental states that we would expect any person who acted intelligently to have, either because the correct decision rules demanded them, or because they are necessary ingredients in the production of any action. Other mental states play no necessary role in the production of intelligent action. Call those the essentially optional mental states. The view that I have argued for is neo-Stoicism about the essentially optional mental states: there are no circumstances in which a person is rationally required to be in an essentially optional mental state.

I'm convinced that the right dividing line is between the essentially optional mental states and the, well, essential ones. We can be rationally required to have non-doxastic attitudes. So, for example, I think it is irrational to believe that $x$ is the unique all-things-considered best of your alternatives, but not to prefer $x$ to your other alternatives. So, some preferences are rationally required of you in certain circumstances, and not just as a result of enkrasia or means-end coherence. These preferences are not beliefs.

Though the preceding argument is mostly right, I think, it does require some qualification. Some people might not themselves accept any kind of neo-Stoicism; they would think in certain circumstances, certain essentially optional attitudes, such as anger, are rationally required. They might have the view, for example, that if a person thinks that another has wronged them very badly and very unjustly, then the first person is rationally required to be angry with the second. Imagine that such a person finds themselves in those circumstances, realizes it, and thinks they are rationally required to be angry. Are they rationally required to be angry?

This situation raises tricky questions about akrasia. I myself agree with the tradition that thinks that akrasia is in general irrational, since it is a way of doing less well than one can by one's very own lights. Of course, it sometimes happens that by being akratic, one in fact ends up doing better, though not by one's own lights. ${ }^{12}$ That might be true in the present circumstances: it might be best for the person who thinks they're rationally required to get angry to remain calm. It might be, then, that we should be glad for some of our akratic behavior. But since I am thinking of rationality in terms of rational requirements, and because I think one is required not to do worse by one's own lights than one otherwise

possi! ble for an agent but cool fear not to be. It wouldn't be if, e.g., the attitudes that compose cool fear are also necessary for warm fear, as cognitivists (like Nussbaum, mentioned earlier) have it. Finally, according to soft neo-Stoicism, in such situations (if the 'ought'-implies-'can' principle is correct), fear will not be rationally required. This may be wrong, but there is an argument behind it (that of Sections 1 and 2), and I can't think of a case where the description in this objection is more compelling than that argument.

12. For this line of thought, see, among others, Arpaly 2002). 
could, akrasia will be irrational. ${ }^{13}$

Even if akrasia is irrational, it remains to specify the form of the rational requirement to avoid it. We have to choose between two kinds of principle: ${ }^{14}$

ENKRASIA $_{N S .} \forall S, \varphi$ : if $S$ believes that $S$ herself is rationally required to $\varphi$, then $S$ is rationally required to $\varphi \cdot{ }^{15}$

ENKRASIA $_{W S} . \forall S, \varphi: S$ is rationally required either to not believe that $S$ herself is rationally required to $\varphi$, or to $\varphi$.

The difference makes a difference here. Suppose, for example, that Titelbaum's (2015) "Fixed Point" thesis is correct-that mistaken beliefs about the requirements of rationality are themselves ipso facto irrational. The non-Stoic under consideration would, then, have an irrational belief about what is rationally required. If ENKRASIA $W S$ is true, then her akrasia has only one rationally acceptable resolution, rather than the normal two: she must rid herself of the mistaken belief; if she doesn't, then she will be irrational no matter what she does. If, on the other hand, ENKRASIA $_{N S}$ is true, then so long as she in fact retains the belief, then she is rationally required to have the emotion. That's not to say that she can't also rationally revise her mistaken belief about the requirements of rationality. If she does, then she is no longer rationally required to get angry, but if she doesn't, then she is so required.

So, supposing the Fixed Point thesis, if ENKRASIA ES $_{S}$ is true but ENKRASIA $N S$ is not, then we need not qualify our soft neo-Stoicism any further, but if ENKRAsIA $_{N S}$ is true, then we do need to qualify it a bit. That qualification isn't hard to formulate; we just add an exception for where the agent believes she is rationally required to be in an essentially optional mental state. Since it's not my aim to argue for or against any one of these theses, I won't say more about whether the qualification is required.

Similar remarks hold for means-end principles, though here it doesn't seem to matter whether the correct principle is wide or narrow scope. Imagine an actor, for example, who knows that to get a particular role, she really has to be sad-it's not good enough just to pretend. That can make it rational for the actor to get sad in various circumstances. I'm less sure that it can make the actor rationally required to be sad in some of those circumstances, but it doesn't seem completely implausible. So, the soft neo-Stoicism I've been defending might require exceptions for means-end principles, too. ${ }^{16}$

13. For defenses of the idea that akrasia is irrational, see Feldman (2005), Broome (2013), Horowitz (2014), and ?; and for attacks on the idea, in addition to the Arpaly, Coates (2012) and Lasonen-Aarnio 2015).

14. For discussion, see, among many others, Kolodny (2005) and Broome (2013).

15. It might be that $S$ is only required to intend to $\varphi$. I'll ignore this complication hereafter.

16. It seems that whether or not someone finds this kind of example compelling often 
Perhaps with some or all of those qualifications, I think soft neo-Stoicism about the essentially optional mental states is true. In what follows, I'll suppress these potential qualifications where they aren't relevant. Now, before explaining why soft neo-Stoicism is true and drawing out some implications of the view, I'll address potential objections.

First, sometimes doesn't the balance of reasons point to adopting some particular 'essentially optional' mental state? For example, we seem to have overall reason to be sad at the misfortune of a loved one.

I want to answer this objection in two ways. First, I am only concerned with rational requirements. I claim that the Stoic isn't rationally required to feel any kind of sadness. But it might be immoral for her not to feel in various ways, and it might also be imprudent. Nevertheless, the source of that 'ought' is not rationality.

Second, the example is actually fairly complex. It might be that, for love to be what it is, it requires feeling sadness at the misfortunes of those one loves. On this view, it is part of love's functional role that it disposes one to such feelings, so that one wouldn't love at all if one didn't have these dispositions. Then, on the condition that one loves, although sadness isn't rationally required, it is conceptually or functionally required. ${ }^{17}$

The second objection continues the first: according to rationalism about morality, some or all moral requirements are requirements of rationality-suppose all. Again, some emotions seem to be morally required, such as sadness at the misfortunes of a loved one. Then some emotions are rationally required. In that case, even the qualified soft neo-Stoicism is false. What I say should be compatible with all the major views in moral theory and metaethics, but if soft neo-Stoicism is true, moral rationalism is false. That's one version of the objection. Another, constitutivism, more particularly attacks my version of soft neo-Stoicism. If morality can be derived from the nature of human agency, so that someone who doesn't in some sense care about being moral isn't even an agent, we would expect anyone who counts as an agent to exhibit at least some of the morally required emotions. So these emotions aren't essentially optional after all. ${ }^{18}$

depends on whether or not they accept the following principle: $\forall S, F$ : if $S$ is rationally required to cause herself to be $F$, then $S$ is rationally required to be $F$. That's because you can say that the actor only ought to cause herself to be sad. Possib! le counterexamples to the principle include situations where one (knows one will) benefit overall from being irrational, as in Schelling 1960 18); if this principle were correct, it would be rationally required of someone that they be irrational. I myself don't mind rational dilemmas like this, but some do, and so that's one of the reasons I say that means-end coherence provides one potential qualification of our soft neo-Stoicism.

17. There needn't be requirements that $\psi$ given that $\phi$, even when $\square(\phi \rightarrow \psi)$ (Broome 2007).

18. For versions of constitutivism, ! see Korsgaard 2008) and Velleman (2000). 
Moral rationalism is a contentious theory, and I find extant criticisms of the general strategy compelling. ${ }^{19}$ Even if those criticisms are unsuccessful, however, I'm not sure the soft neo-Stoicist and the constitutivist need clash. That's because I doubt we would be using 'rational' in the same way-my use only necessarily concerns intelligibility at a time, whereas their usage concerns things like practical identities.

If this section's argument is right, then you should think an appropriately qualified soft neo-Stoicism is true of the essentially optional attitudes. But I haven't explained why it's true. In the next section, I will attempt an answer. But even if the explanation were wrong, my results in Sections 3 and 4 would still stand, though slightly etiolated.

\section{Rationality and Essential Optionality}

I said that an intuitive and informal gloss on ' $\varphi$-ing is rational' is ' $\varphi$-ing makes

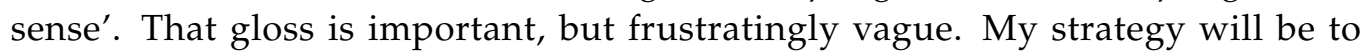
give it a little more content, and use that content to explain the truth of qualified soft neo-Stoicism. More specifically, I'll offer some constraints that only partly specify how "makes sense" should be understood, which is enough for my purposes. I intend this section to be an explanatory clarification and sharpening of the argument from Section $1 .^{20}$

Gibbard says that 'rational' and 'make sense' carry "a kind of direct and flavorless endorsement, taken from the point of view of the person whose acts or feelings are being assessed" (1990. 7). I think Gibbard is right to think of the endorsement as in some sense coming from the evaluand's point of view. But we shouldn't say that someone's $\varphi$-ing is rational just when they endorse it. The trick is to construct the relevant point of view.

I earlier distinguished between essentially optional attitude-types and essential ones. I claimed that the essential attitude-types are the ones a person needs in order to be capable of intelligent action, i.e., intelligent choices in decision problems. That's because, without the essential attitudes-minimally belief and preference-one has no perspective from which to choose. The sense of 'rational' I have in mind is connected with intelligent choice: it requires agents to have those mental states necessary for determining a perspective that makes intelligent choice possible, and then requires that they make intelligent choices. This leads to a distinction between attitudes and states that are required for determining the agent's perspective, and those that aren't. Emotions and tastes belong to the second category, since none of them are necessary for the agent to have a

19. See, e.g., Williams 2011 . Chapter 4) and Enoch (2006).

20. Thanks to an anonymous referee for comments that led to a very substantial revision, and, I hope, improvement of this section. 
perspective from which to act.

I claim that the following is true of that second category:

Permission to Maximize. $\forall S, \varphi$ : $S^{\prime}$ 's $\varphi$-ing is not rationally required if the expected utility of $S^{\prime}$ s not $\varphi$-ing is greater than the expected utility of $S^{\prime}$ s $\varphi$-ing.

As confirmation, consider that it seems like the following explanation-type for not having a particular emotion $E$ is persuasive: it would do no good to have $E$, so instead I'll not have $E$. For example, even if $X$ does $Y$ a serious injustice, we, or at least I, would not find $Y$ irrational should they say, "it'd do no good to be angry, so instead I'll stay calm." If I subscribe to an honor-based morality, I might think $Y$ ought to be angry for other reasons. But an emotion's prospective uselessness seems to be sufficient to avoid charges of irrationality-I can no longer complain that $Y^{\prime}$ 's lack of anger makes no sense. Similarly, if I find it useful to eliminate my enjoyment of a particular food's taste (let's suppose eating it is making me unhealthy), then it is not irrational to make myself stop enjoying that taste. In general, for mental states and attitudes that aren't necessary to determine the agent's perspective, not having that mental state make! s sense once one is convinced that the person's expected utility would not be maximized were they to adopt that mental state.

I don't claim that Permission to Maximize is true of those attitude-types that are necessary to determine the agent's perspective, namely her doxastic states and her preferences or desires. It might be, but that's a controversial claim. ${ }^{21}$ It's $^{\prime}$ controversial because, first, it seems like when evidence and expected utility tell one to believe different things, one (rationally) ought to believe with the evidence, and second, it seems like some preferences are not rationally permissible, e.g., preferring to be so thin that one dies to living. ${ }^{22}$ All I need for my purposes is the truth of Permission to Maximize for attitudes and states that aren't necessary for determining the agent's perspective.

Before I show how Permission to Maximize explains why my qualified soft neo-Stoicism is true, I want to highlight three of its features. First, it makes good on the plan to bring in the agent's own perspective, by talking about her expected utilities for various actions.

Second, it is not a biconditional, for reasons in the introduction: one is not rationally forbidden from grieving the death of a parent, even when its expected utility is lower than not grieving. When a feeling is apt or fitting, for all I've said it might very well be rational even when having that feeling has less expected utility than not having it. But an agent should always be rationally permitted to maximize expected utility. The view is similar to Scheffler's (1994) moral

21. See, e.g., Rinard (in press).

22. See Gibbard (1990). Thanks to an anonymous referee for drawing this to my attention. 
theory, where one is always morally permitted to bring about the best states of affairs, even if one isn't always morally required to do so. Once one has one's perspective, it's always rational to maximize expected utility-even if it can also be rational not to bring about the most utility.

Third, the principle allows it to be rationally required to not have a particular attitude when the attitude is very significantly unfitting. For example, it might be genuinely irrational for you to feel extremely sad over spilled milk. Here's a way that might be that harmonizes well with what I've said in this section. Feeling extremely sad that $p$ seems to require the at least dispositional belief that $p^{\prime}$ s truth is seriously bad. But that belief is irrational, i.e., someone who has it, or perhaps also a corresponding preference against spilled milk, wouldn't make sense. Of course, it would were the milk very valuable in the circumstances. But generally that won't be true. So everything I've said is compatible with our being rationally required not to have particular emotions, even if it is not compatible with our being rationally required to have them. ${ }^{23}$

In considering the rational permissibility of an agent $S^{\prime} s \varphi$-ing, there are two possible cases: given $S^{\prime}$ s overall doxastic state, $S$ 's $\varphi$-ing is required in order to maximize expected utility, or it isn't. If it is, then the version of soft neo-Stoicism I endorse offers no verdict: this is a case where means-end coherence might very well require the agent to $\varphi$. If it isn't, then Permission to Maximize says that $S^{\prime}$ s not $\varphi$-ing is rationally permissible. So, Permission to Maximize explains the truth of (qualified) soft neo-Stoicism.

Finally, why is Permission to Maximize true of the essentially optional attitudes and states? I'll set aside the view on which it's also true of the essential ones, though that might be right. If it's true only of the essentially optional attitudes and states, it will be for the following reason. We ought to have the best perspective-the best beliefs and preferences-we can, given our evidence. But once a person's perspective has been determined, a fully rational person with that perspective may do best by her own lights, i.e., she may maximize expected utility. Permission to Maximize is true of the essentially optional attitudes and states because rationality is at least permissively instrumental, once an acceptable perspective-minimally beliefs and preferences-has been established. ${ }^{24}$ It's at least permissively instrumental because a person! will always make sense when they maximize expected utility by their own rational lights. ${ }^{25}$

23. Thanks to an anonymous referee for pressing me on this point.

24. Parfit (1984 Chapter 1) moots an even more instrumental conception of rationality.

25. I stress that I am interested in rationality in the sense of intelligibility in particular and not in fittingness. This matters because PeRMission to MAximize is probably false for fittingness. The reason is familiar. I might witness my companions do something embarrassingly funny, but I bring myself not to be amused so that I don't compound their embarrassment. This is a wrong kind of reason; it is fitting to find it funny. (See, e.g., $\mathrm{D}^{\prime}$ Arms and Jacobson, 2000 , and Rabinowicz and Rønnow-Rasmussen, 2004) What matters for me is that getting myself not 
My version of soft neo-Stoicism is non-trivial, then, because it is non-trivial that Permission to Maximize applies to the essentially optional attitudes, e.g., emotions and tastes. It's not stipulative or definitional that it does; an opponent might coherently deny that not being, say, jealous in a given case makes sense just because not being jealous does us more good than would being jealous. I claim that, though that denial will be coherent, it will not be plausible. I also claim that it happens extremely often, and can happen more often, that rationally permissible perspectives determine that having a given emotion or taste will not maximize expected utility. As proof of the non-triviality, notice how substantive it is whether that principle applies to belief and preference.

That's my attempt at an explanation of why soft neo-Stoicism is true. Next I'll turn to drawing out some of its implications and showing what interesting work it can do.

\section{Epistemological Consequences}

In this section, I'll make an argument for the conclusion that, given some compelling views about how we come to know about the properties associated with essentially optional attitudes, soft neo-Stoicism has interesting implications for the epistemology of those properties. It also allows us to provide a minimal characterization of "subjective" as applied to predicates and properties like 'tasty' and tastiness.

Suppose a view like Johnston's is correct: for a large range of evaluative predicates, "the utterly determinate versions of such determinables as the beautiful, the charming, the erotic (in the narrower sense), the banal, the sublime, the horrific and the plain old appealing and the repellent ... would be inaccessible to beings without an appropriate sensibility" By that he means, without experiencing the relevant affects, one is "ignorant of the relevant determinate values" (2001: 182-3). He seems to mean that one would lack even the concepts involved, but it might simply be that our judgments of what exemplifies these qualities will be unjustified. The minimal thesis: for a certain class $\mathcal{F}$ of predicates, without having the right affect, we cannot make justified judgments that apply those predicates. To be justified in thinking that, say, an apple is a certain kind of appealing, one has to feel the appeal of the apple. ${ }^{26}$

to be amused (and therefore not being amused) is also rational, since it furthers my aims of not embarrassing my companions. We manage our amusement and other attitudes like this very frequently, sometimes even without noticing. Thanks to an anonymous referee for the worry.

26. For the purposes of this paper, 'j! ustification' (and 'justified', etc.) should be read as 'doxastic justification' rather than 'propositional justification', since, although I believe the theses read with 'propositional justification' are also true, all I need is them read with 'doxastic justification'. 
Either version is probably wrong as it stands, for reasons he doesn't consider. That we cannot even make the judgments is a strong claim, and, because what I say can be anaphoric on what you say, likely false. Suppose A is sighted and B is visually impaired. The following dialogue is perfectly fine:
A: Steve Buscemi is so incredibly hot.
B: I take your word for it. So that means there's an incredibly hot actor in Fargo. Huh, the things you learn.

This example works against the minimal thesis that such people can't be justified in their judgments. But something like it seems right: original justification for applying these predicates must come from affective engagement with the objects. This is a notoriously difficult concept to define, and for my purposes it's enough to say that without affective engagement with a given object or object-type, a person cannot be justified in applying these predicates to that object or tokens of that type other than by testimony.

It also seems plausible that one is rationally required not to believe what one is not justified in believing. That might even be terminological, though I don't insist on that. Now, imagine we have someone experiencing some scene with their five senses. For all the predicates ' $F$ ' $\in \mathcal{F}$, however $F$ we believe something in the scene is, we cannot say that such a person ought (rationally, or epistemically) to believe the same thing, even if they see, hear, smell, taste, and touch the same things we do. For it is not the case that they ought rationally to have the affect necessary for justification. ${ }^{27}$

It's important to be clear about what this shows. This result holds just when an agent is not required to have the given affective attitude. So, for example, it might only hold in the absence of the enkratic or means-end coherence constraints' kicking in. It also requires that the agent doesn't have justification some other way (i.e., non-original justification). What's important for me is this. Suppose an agent $S$ is not in one of those possibly exceptional cases. Then, where $p$ is an ascription of $F$-ness to some object, where ' $F^{\prime} \in \mathcal{F}, S$ is not rationally required to believe that $p$. It is an empirically optional proposition, by which I mean

27. Here's the argument in a bit more detail. Let ' $J_{S}(\phi)^{\prime}$ ' mean 'S is justified in believing $\phi$ ', ' $O(\phi)^{\prime}$ mean 'It ought (rationally) to be that $\phi^{\prime}$, ' $A$ ' mean ' $S$ has the relevant affective attitude', and ' $B_{S}(\phi)$ ' mean ' $S$ believes that $\phi$ '. Suppose (i) $O\left(B_{S}(p) \rightarrow J_{S}(p)\right)$ and (ii) $\square\left(J_{S}(p) \rightarrow A\right.$ ). (i) just says that you should believe something only if you're justified in believing it, and (ii) encodes the insight from Johnston. You might worry about the necessitation of (ii); but it's innocuous, since we're not interested in worlds where one can obtain justification with other methods, say, telepathy. From (i) and (ii) we get (iii) $O\left(B_{S}(p) \rightarrow A\right)$. Next, suppose (iv) that $\neg O(A)$, which is a formalization of soft neo-Stoicism. By (iv), we get that there's a world $w$ that's rationally accessible from @ such that $\neg A$. Since by (iii), every world rationally accessible from @ is such that $B_{S}(p) \rightarrow A$. By modus tollens, ' $\neg B_{S}(p)$ ' is true at $w$. But then there's a world rationally accessible from @ such that $\neg B_{S}(p)$, so $\neg O\left(B_{S}(p)\right)$. 
the following: a proposition $p$ is empirically optional iff no belief or set of beliefs whose justification is ultimately purely empirical (non-testimonial and achieved through one of her five senses) can rationally require an agent to believe that $p$, because that agent is not rationally required $\mathrm{t}$ ! o have a particular associated affect.

For example, if I see a particular animal, but experience no revulsion or the like, then I am not required to believe that it's gross, and that's because I'm not rationally required to feel the revulsion, by soft neo-Stoicism.

It's an interesting question how to extend this account to more complex propositions. For conjunctions, it's easy enough: one needs justification for each conjunct of a conjunction. But other connectives are more difficult, owing to the difficulty in setting out explicit constraints on justification for propositions involving those connectives. I doubt there are any hard and fast rules here. We can get justification for a disjunction by getting justification for just one of its disjuncts, or by something like reductio ad absurdum. Negation seems to me to behave largely like propositions without negations, but I'm not completely confident in that. With quantifiers, I assume that universal generalization works like conjunction and existential generalization like disjunction, so that we can say something definite only about the former. In other words, you can't read whether or not a proposition is empirically optional off of its syntax. One needs to know more about the a! ctual semantic content, and about epistemology. ${ }^{28}$

With the notion of empirically optional propositions, we can define other important notions. Say that a proposition is subjective iff it is empirically optional. A sentence in context is subjective iff it expresses a subjective proposition. ${ }^{29}$ An utterance is subjective iff it expresses a subjective sentence. A property $F$ is subjective iff any simple judgment that $x$ is $F$ is empirically optional, and a predicate ' $F$ ' is subjective iff ' $F$ ' stands for a subjective property. A belief that $p$ is subjective iff $p$ is a subjective proposition, and an attitude is subjective iff it has as one of its components a subjective belief or an essentially optional attitude. ${ }^{30}$

In other words, I claim to have given an analysis of a very important but rather elusive concept: SUBJECTIVE, in a sense that has recently gotten a lot of play in philosophy and linguistics. ${ }^{31} \mathrm{I}^{\prime} 11$ now note a few interesting features.

28. The problem is essentially that justification logic is so weak. While one can show in the most commonly accepted logic that, e.g., $J_{S}(\phi \& \psi) \leftrightarrow J_{S}(\phi) \& J_{S}(\psi)$ or $J_{S}(\phi) \vee J_{S}(\psi) \rightarrow$ $J_{S}(\phi \vee \psi)$, little else is quite so tidy. For more, see Artemov (2011).

29. Again, it is important to keep in mind the point I just went over: this will not in general be determinable from just the syntax, even if we know whether the constituents are subjective.

30. Thanks to an anonymous referee for pressing me to extend my account of subjectivity to attitu! des, especially the cool ones.

31. See, for example, Lasersohn (in press), MacFarlane (2014), Stephenson (2007), and Kennedy (in press). I could name many more. For rival attempts at an analysis that I think fail, see Wiggins (1995) and Wright 1992). 
First, of course, it is epistemic rather than semantic or metaphysical. In the first instance subjectivity concerns rational requirements to believe propositions, and only derivatively the semantics of predicates that figure in sentences that express those propositions. So, for example, nothing in the nature of subjectivity as such commits us to contextualism, the view that the content of sentences with subjective predicates changes according to the perspective of the speaker or speakers, or to relativism, the view that sentences' truth values differ across the perspectives from which those sentences can be evaluated. We also need not have the commitment that subjective propositions are neither true nor false, or that there is no fact of the matter whether a given subjective proposition is true. I haven't argued against any of those views, nor is it my intention to; it is just a good feature of this analysis that it doesn't by itself commit us to any further contentious clai! ms like these.

Second, most but not all of the properties normally grouped together under the relevant sense of 'subjective' probably count as subjective in this sense. Most individual cases will require specific argument, and I haven't done that for basically any of the relevant properties, though I have suggested which kinds are likely to count, e.g., sexiness. I suspect it will be most of the so-called 'responsedependent' properties, such as boringness and importance, along with personal taste (e.g., tastiness) and aesthetic properties (e.g., daintiness). Secondary qualities have often been lumped together with these, and it's easy enough to see that my definition cannot count them as subjective. I presumably am rationally required to think that, for example, my bed sheets are black, and I have no other justification for the belief than that I saw them. The same goes for sounds, smells, etc. In general, a good heuristic for when a property will be subjective in this sense seems ! to be this: would a being with no essentially optional mental states have a concept or a predicate for that property? If yes, then probably it is not subjective, and if no, probably it is. This heuristic is variably useful; for some properties, I would say it is pretty easy to see that it definitely would or wouldn't pass that test, but for others it is difficult to say. I'll proceed under the assumption that roughly the properties I listed above are in fact subjective in my sense.

Third, this characterization allows for a quick explanation of why arguments over subjective claims seem to be wastes of time, without assuming there's no (absolute) answer about who's right. ${ }^{32}$ This phenomenon is familiar: I think a particular dish tastes great; you think it tastes gross. We begin to argue, but quickly stop-we're getting nowhere. Why should this be?

I can get justification for a subjective belief $p$ even in the absence of the right kind of affective engagement if, for example, I get testimonial evidence for $p$. You give me some-you believe that $p$. But I'm initially unpersuaded; I have a

32. For an alternative, partly semantic, partly pragmatic account, see Egan 2010. 
firm enough belief in $q$ (which conflicts with $p$ ) that, though I have indeed incorporated your testimony into all of my evidence, I don't form the belief that $p$. To get me to believe $p$, you can try to either undermine my trust in my own affective engagement with the relevant object (say, by pointing out that I'm currently suffering from food poisoning), or you can get me to have the sort of affective engagement that you had with the object. The first of these strategies can be accomplished with verbal argument, but only in relatively rare circumstances; and the second cannot-at some point, feeling has to do its work, and you can only set me up for that, not rationally compel me, given soft neo-Stoicism. It can happen, for example if you point out features of a work that I hadn't noticed or attended to, but it can't happen by rational force. Thus, if we can see there are no particular reasons to distrust my abilities to affectively engage, and if new varieties of affective engagement don't seem forthcoming, then we should conclude that further argument would be a waste of our time.

Sometimes it happens that you've had an affective engagement that justifies you in believing $p$, and I have had no kind of relevant affective engagement and therefore don't believe any $q$ that conflicts with $p$. The futility of extended argument in this sort of situation arises for the same reason. If your initial testimony doesn't convince me, and I never do have your sort of affective engagement (which, again, it's hard to argue me into having), then I will not be justified in believing $p$, and so ought not to.

Fourth, and relatedly, it can account for how disagreements about subjective claims can be faultless. Some have doubted even the possibility of a faultless disagreement, while others have taken it to be criterial for subjectivity. ${ }^{33}$ Here's the argument that it's impossible. First, $p \vee \neg p$. Suppose $p$. Then the $\neg p$ party believes something false. Believing something false is a mistake. Second, suppose $\neg p$. Then the $p$ party believes something false, a mistake. So, either way, one party makes a mistake. So there are no faultless disagreements. I've recounted this argument not because I think it works (I'm not sure), but to structure the debate: if one takes faultless disagreement to be possible, they'll have to choose which premise to reject. A relativist, for example, might reject the premise that believing someth! ing false is a mistake, since though false by my lights, $\neg p$

33. For the former, see Wright (2001) and Kölbel (2004), and for the latter, see Kennedy (in press) and Richard (2008). 
might be true according to the other person's perspective. ${ }^{34}$ While others do reject realism, perhaps in a way other than by defending relativism, most who don't like that kind of move have tended to deny that believing something false is a mistake, at least in the relevant sense of 'mistake' related to judgments of faultlessness. 35

Schafer (2011), for example, defends this response in detail. The idea is that in a given aesthetic dispute, we can say that there is faultlessness when each forms their aesthetic beliefs in line with the policy they each individually endorse. So, although in fact one or both parties must be mistaken with respect to the truth of their judgments, they might be blameless in this regard. They are just following their epistemic policies.

Schafer is of course right that this is one sort of faultlessness. But it just amounts to an enkratic constraint, which governs at least a large amount of our mental states. This response, then, doesn't preserve anything distinctive about faultless disagreements like those involved in aesthetics. The trouble is that that faultlessness does seem distinctive in some way.

What I've said can illuminate faultless disagreement in two ways. First, I can secure faultless lack of agreement. For some predicates-the ones from class $\mathcal{F}$-and thus the properties they stand for, you can have two people with exactly the same testimony from their five senses and the same priors, and still have one rationally disagree with the other. That is, if the one person believes that $p$ in part because they have affectively engaged with the right sort of object, and the other has not so affectively engaged, the second party is not rationally compelled to accept $p$, even if the first one is. The normative upshot of a perceptual experience can be different for two people, even if they share all their priors, since one will not be rationally compelled to form a subjective belief that the other might be.

Soft neo-Stoicism also helps with faultless disagreement, though here it needs

34. See, e.g., Kölbel 2004 70-1), who endorses the following:

TR. It is a mistake to believe a proposition that is not true in one's own perspective.

It's clear from context that Kölbel considers this to be the strongest correct link between something's untruth and its being a mistake. Other cases are a bit harder. MacFarlane (2014), e.g., goes through a lot of possible notions of faultless disagreement. From there, he can be read in (at least) three, not mutually exclusive ways: first, perhaps, as rejecting the premise that neither party is making any mistake-in which case, relativism wouldn't help to establish this very strong version of faultless disagreement. Second, he can be read as agreeing with Kölbel as far as constitutive norms of belief and assertion go, since he affirms something like TR himself. Thirdly, he seems to reject the theoretical importance of the multiply ambiguous phenomenon going by 'faultless disagreement'. It's not especially important for my purposes whether he endorses all three of these positions, or which particular ones; in discussing Kölbel's less! nuanced version, I only mean to indicate one of the (many) options.

35. The view ultimately derives from Wright (1992), though Kölbel considers similar moves. 
some plausible auxiliary premises. Here's the sort of case I'm imagining. A thinks $p$, and B thinks $\neg p$. They have all the same empirical evidence, and the same prior credences. A is rationally required to believe $p$ because of having an affective engagement $X$, and $B$ is rationally required to believe $\neg p$ because of having a different affective engagement $Y$, where $X$ and $Y$ are both attitudes of type $M$. Now, for all soft neo-Stoicism says, it could be that one is permitted only to have $X$, if one has an $M$-type attitude in that situation at all. But suppose we're in an attitudinally permissive case, where both $X$ and $Y$ are rationally permitted. I haven't argued that there are these cases; there really ought to be, though: it should be permissible for me to just like vegemite, and you to just not. Even so, we don't yet get rationally faultless disagreement, since it might be! that A or $\mathrm{B}$ is also rationally required to have $Y$ or $X$, respectively. In that case, $\mathrm{A}$ or B's justification for their respective beliefs would be defeated, thus not rationally held. Soft neo-Stoicism rules out this possibility: neither agent is rationally required to have $X$ or $Y$ at all. To sum up: so long as there are some (non-doxastic) attitudinally permissive cases, soft neo-Stoicism guarantees the possibility of rationally faultless disagreement, even if doxastic permissivism is false. ${ }^{36}$ This should be a welcome result, too, at least if you worry that extant anti-permissivist arguments are successful.37

Fifth, an additional moral is that one can have entire communities in which no member is rationally compelled to make a subjective judgment, even given maximal empirical familiarity with the objects of those judgments. This isn't to say such communities wouldn't be 'missing out' in any meaningful sense. But whatever that sense might be, it wouldn't be the sense in which one would be missing out when they don't believe an empirically required proposition (e.g., the explanation of magnetism). This explains why cultural and species relativism about these claims has been popular for as long as it has..$^{8}$ If other cultures cultivate different habits of feeling, etc, it wouldn't at all be surprising that they differ. ${ }^{39}$

Sixth, and lastly, moral properties might be subjective in this sense, especially if sentimentalism is true..$^{0}$ This would happen if, e.g., guilt, specifically prospective or hypothetical guilt, were necessary to be justified in believing some moral proposition. If so, although an individual without that feeling might not be rationally compelled to have that belief, it might be morally necessary to feel that prospective or hypothetical guilt-if they are to have originally justified moral

36. The existence of such cases is compatible with the falsity of permissivism, since A and $B$ differ in their total (not just empirical) evidence: A learns that she's had $X$, and B learns that she's had $Y$.

37. See White (2005), Feldman 2007), and Greco and Hedden (in press).

38. See, e.g., Sextus Empiricus (1933), written in the second or third century.

39. See, e.g., Tsai, Levenson, and McCoy (2006).

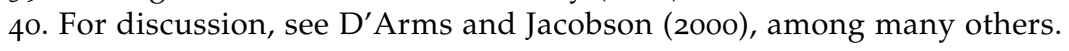


beliefs at all. In that case, the compulsion to have a given moral belief will itself be in part moral. But I won't speculate further.

So, soft neo-Stoicism allows us to give a powerful analysis of an evanescent concept, subjective, and to thereby explain many of its most puzzling features. What I said about the subjective raises a number of important questions, particularly about realism. The difficult issues involved concerning realist treatments of the subjective turns on whether or not we think that our senses are better guides to the way the world is, independent of us, than our affective engagement with

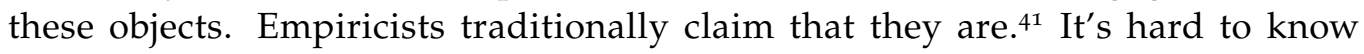
how to begin to answer that question in a rigorous way, and so I would be content to make progress on the more tractable issues in the area, as I've tried to do here.

Soft neo-Stoicism does even more interesting work, though: it can explain why so many versions of REFLECTION are implausible, and even why REFLECTION about credence itself is open to counterexamples. In the next section, I'll elaborate on and justify these claims.

\section{What Coherence Requires}

REFLECTION about credences, roughly the view that your credences at a time are rationally required to match your expectations of your future credences, has proved very controversial for a long time..$^{42}$ The idea has proved resilient, not just because of the arguments for it, most famously some diachronic Dutch books, but also because there seems to be something very intuitive about it. For example, it's often described as a norm for deferring to experts, where the expert is the future version of the agent herself. ${ }^{43}$ I think that's basically right, at least when one is clear about what one means by 'expert'. According to Reflection, when you learn what your future self thinks (and that they will not lose information or reasoning abilities), you ought to defer $\mathrm{t}$ ! o them, since they are at least as informed as you are on the relevant matters. In what follows, I'll sometimes use the language of 'experts' and 'deference', for those who find it helpful; but this is just one way to put things, and not a way I mean to commit myself too strongly. Anyhow, whatever the reason, I think there is good reason to be tempted by some version of REFLECTION.

41. See, e.g., Travis (2004 248).

42. For an initial presentation of the view, see van Fraassen (1984). For some famous counterexamples, see, e.g, Talbott (1991), Christensen (1991), and Arntzenius (2003). For defenses, see van Fraassen (1995) and, more recently, Briggs (2009).

43. Hedden (2015b) at least thinks of expert deference as a replacement for Reflection, but others think REFLECTION just is a norm for deferring to experts. See, among others, Briggs 2009 59), Christensen 2010 135), and Evnine 2008). The use originates with Gaifman (1988). 
It's striking that nearly all of the discussion of REFLECTION has been limited to doxastic states, either credences or full beliefs. ${ }^{44}$ Nearly all, but not all; Arntzenius (2008) argues for a version involving desirability. ${ }^{45}$ No one to my knowledge has discussed whether REFLECTION could plausibly be extended to attitudes like hate or jealousy. It turns out that it can't. ${ }^{46}$ Soft neo-Stoicism can help explain why. Before I turn to those cases, though, I want to discuss how soft neo-Stoicism can help account for the failure even of REFLECTION applied to credences and full beliefs. The same kind of explanation will then transfer over to REF! LECTION for other attitudes.

Ross and Schroeder (2013) devised an interesting argument against invariantism about an expression $e$, i.e., the view that the semantic value of $e$ does not change as a function of the context, the speaker's or the hearer's. Consider the following case from Spencer 2016):

Chug. Bill, a freshman in college, utters the sentence, 'Chugging beer is fun', while correctly predicting that in thirty years, when his own son is a freshman in college, he will sincerely utter the sentence, 'It is not the case that chugging beer is fun'.

Since Bill knows (let's stipulate) that he will sincerely utter the sentence, he knows he'll believe its contents. Since none of the usual qualifications to REFLECTION would kick in, Bill seems subject to REFLECTION, in which case he shouldn't be able to assert now that chugging beer is fun. Yet the assertion seems completely fine. The contextualist can explain this: Bill's utterance as a freshman has different content from his utterance thirty years later ('fun for me as I am now' vs. 'fun for me as I will be in thirty years'). Minimally, the argument purports to show invariantism for taste predicates, e.g., relativism, is false.

Actually, though, REFLECTION will fail in such cases even if we assume contextualism is right. To see how, suppose that 'fun' means 'fun for $X$ at $t$ ', where $X$ is the agent of the context of utterance and $t$ is the time of the context of utterance, and 'not fun' means 'not fun for $X$ at $t$ '. Also suppose that 'fun' and 'not fun' are empirically optional predicates, i.e., assume that, in absence of non-original justification, one is not rationally required to believe a given simple predication of them (a predication of the form ' $O$ is $F^{\prime}$ or ' $O$ is not $F$ ') without affectively engaging in the right way with $o^{\prime}$ s $F$-ness or lack thereof (if you disagree, it's easy enough to vary the example to one that is clearly empirically optional). ${ }^{47}$ Call freshman-Bill 'Bill $F r$ ' and dad-Bill 'Bill ${ }_{D}$ '. Is Bill $F r$ rationally required to believe that chugging beer is not fun for Bill ${ }_{D}$ ? I claim not: even if Bill ${ }_{F r}$ learns

44. For the latter, see Bovens (1995).

45. For an attack on Arntzenius's defense, see Harman (2009) and Hedden (2015a).

46. Perhaps this fact, or its obviousness, somehow explains the neglect of such principles. I doubt that it's obvious, though.

47. For more on this notion, see again Section 3. 
that $\mathrm{Bill}_{D}$ will accept the sentence 'chugging beer is not fun', and concludes that Bill $_{D}$ believes that chugging beer is not fun for Bill ${ }_{D}$, it's possible given what Bill $_{F r}$ knows that Bill ${ }_{D}$ won't be rationally required to believe that chugging beer is not fun for Bill ${ }_{D}$. That's because if Bill ${ }_{D}$ comes to that view just as a result of not enjoying the beer, he was not rationally required to not enjoy it, and therefore not rationally required to believe that chugging beer is not fun for $\mathrm{Bill}_{D}$. Bill ${ }_{F r}$ can only be rationally required to believe that chugging beer is not fun for Bill ${ }_{D}$ if he can know Bill ${ }_{D}$ himself will be rationally required to hav! e that view, but Bill $_{F r}$ cannot have that knowledge, given the truth of soft neo-Stoicism. (Bill $D$ could, for example, have forced himself to be more open to it. $)^{48}$

Here's a different way to put the point. People are rationally required to believe the contents of testimony from those acknowledged by those people as experts (in the relevant ways) only if they also believe the experts themselves were rationally required to believe those contents. In cases where the experts very well might have gone beyond what is rationally required of them, people who hear the testimony are not rationally required to join them in this. So, even if $\mathrm{Bill}_{D}$ is an acknowledged expert about whether chugging beer is fun for $\mathrm{Bill}_{D}$, that doesn't mean that $\mathrm{Bill}_{F r}$ needs to believe what Bill $_{D}$ does about that, since Bill $_{F r}$ has reasonable and salient doubts that Bill ${ }_{D}$ 's beliefs here are rationally required. So, I'm not saying it would be impermissible for Bill ${ }_{F r}$ to believe that chugging beer is not fun for Bill $_{D}$, but just that it isn't rationally required. It might be that Bill $_{F r}$ is within his rational rights to $b$ ! elieve that chugging beer is not fun for Bill $D$; I just claim it is not rationally required, since it won't be rationally required of $\mathrm{Bill}_{D}$ that he not enjoy it. 49

So, given that REFLECTION fails in such cases even if contextualism is right, we can see that, first, even the typically qualified versions of REFLECTION fail when applied to subjective propositions, no matter what their semantics, and second,

48. You might worry that this argument will overgenerate cases where people are not rationally required to believe that $p$, even when they are so required. Evidence is often gotten luckily, e.g., by running into a friend on the street. Suppose Iris believes that she ran into her friend, on the basis of her evidence. She wasn't rationally required to have her evidence, so is she not rationally required to believe that she saw her friend? Iris is rationally required to believe that she saw her friend, once she had that perceptual experience, i.e., Iris is rationally required (in a wide-scope way) to believe that $p$ if she has evidence $e$. In the case as stipulated, $\mathrm{Bill}_{D}$ might be rationally required (again, wide-scope) to believe that chugging beer is not fun if he tries chug! ging beer and finds it dull. But, since Bill ${ }_{D}$ is not rationally req uired to find chugging beer dull, Bill ${ }_{D}$ won't be rationally required simpliciter to think that chugging beer isn't fun. There is nevertheless a difference between evidence like Iris's and experiences like Bill's: if earlier Iris finds out that Iris will have evidence $e$, then (except in weird cases) Iris will herself have $e$ (at least if $e$ is propositional); the same is not true for things like finding some activity dull. So, there are some important asymmetries between the cases. The upshot is that this reasoning doesn't overgenerate.

49. Thanks to an anonymous referee for pressing me to clarify my argument here. 
that a Ross and Schroeder-type argument against invariantism about 'fun' won't work..$^{50}$

I now turn to versions of RefLECTION meant to apply to other kinds of attitudes. Consider the following case:

Hatred by Testimony. Maryam's friend Leena, who knows the sort of person Maryam will hate, has met Professor Z., while Maryam has not. Leena tells Maryam that Maryam will hate Professor Z., but doesn't say anything more-she doesn't say what features possessed by Professor Z. will inspire hatred in Maryam. Maryam herself takes Leena to be extremely reliable about this, and so forms the belief that she will hate Professor Z., that her reasons will recommend hating him, and that she will suffer no serious cognitive mishaps along the way.

Maryam passes the usual tests for Reflection to apply to her, if it does. And yet I take it as pretty clear that she is under no rational requirement to hate Professor $Z$. If she doesn't hate him, we would be wrong to criticize her as irrational. That is, the following principle, whichever of the usual qualifications one adds, seems false:

Hatred Reflection. $\forall S, x, t, t^{\prime}: S$ is rationally required to hate $x$, given that $S$ expects to hate $x$ at $t^{\prime}>t$.

Remember, Maryam expects not to (and, let's add, does not) lose any relevant information, doesn't drink or do any drugs, and all the rest. And yet she still clearly seems not subject to any such rational requirement.

Interesting things happen if we vary the circumstances a bit. Suppose she believes she is rationally required to hate all $F$ s, for example all racists. Even if she knows she will hate Professor Z., she need not hate him so long as she isn't aware of his racism, but once she becomes aware of the racism, then it seems plausible that she is rationally required to hate him. More generally, agents can be made rationally required to hate something or someone if they are acquainted with some feature that makes the thing or person worthy of their hatred. This is a bit puzzling, since acquaintance doesn't seem to be an important feature when one considers which attitudes are rationally required, permitted, or forbidden.

So, we have two kinds of data: Hatred Reflection fails in cases like Hatred by Testimony, but we can seem to generate some rational requirements when the person knows some feature of the thing that makes the thing worthy of hatred. Before saying how I think the explanation ought to proceed, namely by appealing

50. In fairness to Ross and Schroeder, they target the epistemic modal 'might' rather than 'fun'. I think a similar reply would work in that case, but it would take much more work to set up than I have space for here. 
to soft neo-Stoicism, I'll argue against a very natural explanation appealing to an 'ought'-implies-'can' thesis.

Perhaps it is somehow psychologically impossible to hate without the hater's taking themselves to be aware of some property of the object that would warrant that hate, maybe because of its typically rich phenomenology. If 'ought' implies 'can', then one will not be subject to a rational requirement (i.e., it won't be that one rationally ought) to hate a given thing unless one possesses information about what justifies hating that thing (by one's own lights). Unfortunately, the psychological impossibility claim is just not true, as I'll show.

But first, I want to lodge a different complaint. That 'ought' implies 'can' (OIC) is, of course, controversial..${ }^{51}$ Such doubts are compounded by its being the rational 'ought' at issue. Rationality seems to forbid certain particular belieftypes, e.g., $p \& \neg p$ — but why think it's only psychologically impossible for certain non-contradictory contents to be given up? The problem is that rationality always rules out certain beliefs that might be psychologically impossible to eradicate for some individuals. The rational OIC thesis does have defenders, e.g., Wedgwood (2013), who claims that the rational 'ought' implies the psychological 'can', where the 'can' concerns what is in an agent's psychological control. But suppose that an agent could not discover that she has two beliefs that as a matter of (the most uncontroversial sort of) logic do in fact conflict. On Wedgwood's view, we have to say that this agent is rationally ideal, that she is no way that she ought not rationally to be. That's absurd, since she has contradictory beliefs. I doubt that there is a way to make sense of the claim that the rational 'ought' impl! ies the psychological 'can' that makes it true.

The other problem is that it is not impossible to hate something without knowing some feature which justifies that hatred, at least by one's own lights. So, for example, someone can know that they hate a given person because, of, say, that person's national origin, even while disavowing hating someone for their national origin. Similar examples arise in connection with attitudes like disgust, admiration, and many others of which RefLection seems not to be true..$^{2}$ Take disgust, and consider the following utterance:

(4) I'm disgusted by two men kissing, even though it's not disgusting.

For many of these attitudes, we might have them even when there is no justifying reason to, even by our own lights. It can even happen, as the continuation suggests, that we think the things really are not disgusting. Similar examples involving taste and other attitudes are easily constructed along similar lines. It's

51. For some noteworthy attacks, see Sinnott-Armstrong (1984) and Graham (2011).

52. The general phenomenon has come to be known as 'recalcitrant emotion'; see, e.g., Greenspan 1988) and D'Arms and Jacobson 2003. 
not impossible for us to form these attitudes in absence of taking ourselves to be acquainted with some feature warranting the attitude. ${ }^{53}$

Most importantly, it seems that no matter what the proponent of this explanation offers as psychologically necessary for forming certain emotions, their requirement will be too strong. This is because of the phenomenon known to psychologists as emotional contagion, "the tendency to automatically mimic and synchronize expressions, vocalizations, postures, and movements with those of another person's and, consequently, to converge emotionally". 54

The idea is that we very often converge on the emotions of the people we interact with, just in virtue of their expressing those emotions. Obviously this need not require any acquaintance with an object's particular features, since it requires just the right kind of expressions. So, even the requirement that a person have a partial justifying reason for their emotion is too strong. There is, I think, just no way to salvage the idea that these emotions are impossible. So there is no way to salvage the proposed explanation.

We stand in need of one, and we already have all the resources we need for a good one. Why is Maryam not rationally required to hate Professor Z.? Simple, because soft neo-Stoicism is true: we are not rationally required to have any essentially optional attitude except possibly to make ourselves enkratic or means-end coherent. Hatred seems pretty clearly an essentially optional attitude; if our Stoic did not hate, we would not criticize her as irrational at all-that sort of attitude definitely makes sense.

There's another way to think about this that resembles the explanation given of the failure of doxastic versions of REFLECTION. In a normal credence REFLECTION case, 55 I get a lot of information about what will be the rationally required response. It is not so rare that there is a fairly limited range of credences (or intervals of credences) that are rationally permissible, given some evidence. So, upon learning what credence I will assign, I gain a lot of information about what is rationally required of me. By contrast, when I learn that I will rationally come to have a certain emotion, I get much less information. Since it is never (bracketing enkratic and means-end coherence cases) rationally required of me to bear that emotion, I only learn that I am permitted to have that emotion. ! There isn't any information even likely available that would constrain me to have the emotion. ${ }^{56}$

53. For some other cases, see Gendler 2008.

54. Hatfield, Cacioppo, and Rapson (1992 $153-4)$. See also Hatfield, Cacioppo, and Rapson (1993) and the references therein.

55. For example, where the proposition isn't subjective, in Section 3's sense. Thanks to Jim Joyce for the idea to put things this way, too.

56. Earlier (Footnote 1) I distinguished between soft neo-Stoicism and permissivism. Insofar as they're different, you might think that permissivism offers a competing explanation of the failure of Hatred Reflection and all the rest. So, for example, if I know that it sometimes happens that alternative credence functions are permissible, then learning that I'll adopt some 
But then why is it more tempting to say that, where she believes she's rationally required to hate all virulent racists and she learns that Professor $Z$. is one, she is rationally required to hate Professor Z.? That's because if she didn't (or at least intend to), she would be akratic, one of our explicit potential exceptions. As confirmation of this explanation, I've noticed that people's intuitions about this variation of the case tracks whether or not they believe enkrasia is a rational requirement at all: if they do, then the intuitions go the way I've suggested, and if not, not. ${ }^{57}$ Notice, though, that as one might desire, acquaintance is not playing any special role. In this variant of the case, Maryam starts with the belief that she is rationally required to hate all virulent racists. She then learns that Professor $\mathrm{Z}$. is a virulent racist. That she is rationally required to hate Professor $\mathrm{Z}$. seems to be an easy consequence of those two beliefs; so, she would be rationally criticizable for not having that belief, at least if she at all cares about the matter and what's rationally required of her.

All of this depends on whether enkrasia is a requirement of rationality, and I don't mean to take a strong stance. My point is that we can account for these separate intuitions (acquaintance vs. non-acquaintance cases), if we like enkrasia.

As another point in this explanation's favor, intuition seems to align with whether the mental state at issue is essentially optional or not. Consider, for example, jealousy:

Jealousy by Testimony. Oona's friend Molly, who knows the sort of person Oona will be jealous of, has met Professor X., while Oona has not. Oona herself takes Molly to be very reliable about this. Molly tells Oona that

credence function doesn't yet tell me that I'm required, rather than merely permitted, to adopt it rather than some other credence function. Notice, though, that that explanation works structurally identically to the explanation I provided in terms of soft neo-Stoicism: the strongest thing the agent can learn in such cases is that she is rationally permitted to adopt the relevant attitude. More generally, any view on which the strongest thing the agent can learn in such cases is that she will be pe! rmitted to adopt that attitude will be able to provide the same sort o f explanation that I have. Call such views permitting. Permissivism and soft neo-Stoicism are both permitting views, and so offer the same explanation of these cases. So, they're not competing explanations. The truth of soft neo-Stoicism allows us to provide the permitting explanation of these cases, though the truth of permissivism would do the same.

It's not my purpose to argue against the permissivist's version of the permitting explanation, but rather just to argue that soft neo-Stoicism in fact allows us to give a satisfying permitting explanation. That said, the permissivist does face challenges the soft neo-Stoicist doesn't, beyond the mere fact that soft neo-Stoicism has an argument for it. Soft neo-Stoicism, recall, is universally quantified, which means it will apply to every case in which someone's belief is justified by affective engagement. Since permissivism is only existentially quantified, it need not apply in every case, and (depending on contingent facts) relevant permissive cases might be rare enough that the relevant subjects ought to think they're not in one, and thus ought to conform to Reflection.

57. Thanks here to Brian Weatherson. 
Oona will be jealous of Professor X., but doesn't say anything more-she doesn't say what features possessed by Professor X. will inspire jealousy in Oona. Oona forms the belief that she will be jealous of Professor X., that her reasons will recommend being jealous of Professor X., and that she will suffer no serious cognitive mishaps along the way.

I take it the right thing to say about Jealousy by Testimony and its variations is what we said about Hatred by Testimony. The cases seem extremely similar in what is rationally required when. Consider, on the other hand, cool fear:

Future Fear. Emiko's friend Kotaro tells her that, tomorrow, she will learn something about a mutual acquaintance, Sousuke, that will have her reasonably very afraid of him. Kotaro doesn't say what she'll learn, or anything about why Sousuke is in fact worth fearing. Emiko takes Kotaro to be very reliable on what Emiko finds worth fearing in a person. So, Emiko forms the belief that she will fear Sousuke, and she will have suffered no serious cognitive mishaps.

I take it that the right attitude is fear (or apprehensiveness, etc.) here, and Emiko would be odd and criticizable to know exactly how Sousuke is to be feared. It is, then, plausible that Emiko really is rationally required to fear Sousuke. This is not to say that she is rationally required to have the typical fear phenomenology associated with warm fear-the Stoic can rationally dispense with that, and so can Emiko.

All this suggests that an attitude $M$ is subject to a properly qualified RefLection principle concerning $M$ only if $M$ is not an essentially optional attitude, though individuals can (via enkratic constraints) be rationally required to have a given essentially optional attitude. A fuller look at the various essentially optional attitudes and the complement class would provide a securer basis for this generalization, but I won't undertake that here.

I say 'only if' rather than 'if' not because I think the biconditional would be false, but because REFLECTION even for beliefs has been challenged many times (including here!), and it has come under attack for desire, too. Although I think versions can withstand these challenges, thus strengthening my conclusions, a proper defense of them would be a whole different paper. Nevertheless, there is a very significant difference in prima facie plausibility between REFLECTION applied to beliefs and REFLECTION applied to hatred, so even if neither ultimately works out, I still have explained that difference. ${ }^{58}$

58. For other emotions, Reflection never plausibly applied in the first place. For example, grief doesn't simply require it to be true that my loved one died at $t$, but rather that $t$ is before now (and perhaps in the not too distant past, either). That is, some emotions, like grief, pri! de, and, as is familiar from Prior (1976), relief, seem to require de se beliefs. This is an interesting 


\section{Conclusion}

I attempted to do many things in this paper, so a brief summary should be in order. First, I defined and defended a potentially qualified version of soft neoStoicism about most attitudes. I explained why it seemed to be true, given the sense of 'rational' in play here. I then showed what work soft neo-Stoicism can do: first, it allows us to define up an interesting but elusive notion, the subJECTIVE, and to explain many of its intriguing features; and second, it allows us to show how and why RefLection is false when applied to a great many attitudes, including belief when the propositions at issue are subjective (in the sense of Section 3), as well as warm hatred and fear. The upshot is that soft neo-Stoicism is intuitive and fruitful.

\section{Acknowledgments}

A great many people have helped me with this paper. Thanks to Steve Schaus, Sara Aronowitz, Jim Joyce, Jeremy Lent, Umer Shaikh, Patrick Shirreff, Damian Wassel, and Brian Weatherson for very helpful comments on earlier drafts. Extra special thanks to J. Dmitri Gallow, for going through a draft with a fine-toothed comb; Sarah Moss, for crucial feedback and encouragement; Eric Swanson, for a huge number of helpful suggestions, big and small; and Anna Edmonds, for pushing at the right places. Finally, thanks to two extremely helpful anonymous referees.

\section{References}

Arntzenius, Frank (2003). Some Problems for Conditionalization and Reflection. Journal of Philosophy, 100(7), 356-370.

Arntzenius, Frank (2008). No Regrets, or: Edith Piaf Revamps Decision Theory. Erkenntnis, 68(2), 277-297.

Arpaly, Nomy (2002). Unprincipled Virtue. Oxford University Press.

Artemov, Sergei (2011). Why Do We Need Justification Logic? In Johan van

Benthem, Amitabha Gupta, and Eric Pacuit (Eds.), Games, Norms, and Reasons (23-38). Springer.

Bovens, Luc (1995). " $P$ and I will Believe that not- $P$ ": Diachronic Constraints on

Rational Belief. Mind, 104(416), 737-760.

Bratman, Michael E. (2000). Reflection, Planning, and Temporally Extended Agency. Philosophical Review, 109(1), 35-61.

way in which all these versions of REFLECTION fail, but distant from the one I described in detail. 
Briggs, Rachael (2009). Distorted Reflection. Philosophical Review, 118(1), 59-85. Broome, John (2007). Requirements. In Toni Rønnow Rasmussen, Björn Petersson, Jonas Josefsson, and Dan Egonsson (Eds.), Hommage à Wlodek: Philosophical Papers Dedicated to Wlodek Rabinowicz (1-41).

Broome, John (2013). Rationality Through Reasoning. Wiley-Blackwell.

Christensen, David (1991). Clever Bookies and Coherent Beliefs. Philosophical Review, 10o(2), 229-247.

Christensen, David (2010). Rational Reflection. Philosophical Perspectives, 24(1), 121-140.

Coates, Allen (2012). Rational Epistemic Akrasia. American Philosophical Quarterly, 49(2), 113-24.

D'Arms, Justin and Daniel Jacobson (2000). The Moralistic Fallacy. Philosophy and Phenomenological Research, 61(1), 65-90.

D'Arms, Justin and Daniel Jacobson (2003). The Significance of Recalcitrant Emotion. In A. Hatzimoysis (Ed.), Philosophy and the Emotions (127-145). Royal Institute of Philosophy Supplements (Vol. 52). Cambridge University Press.

Egan, Andy (2010). Disputing about Taste. In Richard Feldman and Ted A. Warfield (Eds.), Disagreement (247-285). Oxford University Press.

Enoch, David (2006). Agency, Shmagency: Why Normativity Won't Come from What Is Constitutive of Action. Philosophical Review, 115(2), 169-198.

Evnine, Simon (2008). Epistemic Dimensions of Personhood. Oxford University Press.

Feldman, Richard (2005). Respecting the Evidence. Philosophical Perspectives, 19(1), 95-119.

Feldman, Richard (2007). Reasonable Religious Disagreements. In Louise Antony (Ed.), Philosophers without Gods (194-214). Oxford University Press.

Gaifman, Haim (1988). A Theory of Higher Order Probabilities. In Brian Skyrms and William Harper (Eds.), Causation, Chance, and Credence (191-219). Kluwer.

Gendler, Tamar (2008). Alief and Belief. Journal of Philosophy, 105(10), 634-663.

Gibbard, Allan (1990). Wise Choices, Apt Feelings. Harvard University Press.

Graham, Peter A. (2011). 'Ought' and Ability. Philosophical Review, 120(3), 337382.

Greco, Daniel and Brian Hedden (in press). Uniqueness and Metaepistemology. Journal of Philosophy.

Greenspan, Patricia (1988). Emotions and Reason: An Inquiry into Emotional Justification. Routledge \& Kegan Paul.

Harman, Elizabeth (2009). "I'll Be Glad I Did It" Reasoning and the Significance of Future Desires. Philosophical Perspectives, 23(1), 177-199.

Hatfield, E., J.T. Cacioppo, and R.L. Rapson (1992). Primitive Emotional Contagion. Review of Personality and Social Psychology, 14, 151-177.

Hatfield, E., J.T. Cacioppo, and R.L. Rapson (1993). Emotional Contagion. Cam- 
bridge University Press.

Hedden, Brian (2015a). Reasons without Persons. Oxford University Press.

Hedden, Brian (2015b). Time-Slice Rationality. Mind, 124(494), 449-491.

Horowitz, Sophie (2014). Epistemic Akrasia. Noûs, 48(4), 718-744.

Hume, David (1975). A Treatise of Human Nature (2nd ed.). L. A. Selby-Bigge (Ed.). Clarendon Press.

Johnston, Mark (2001). The Authority of Affect. Philosophy and Phenomenological Research, 61(1), 181-214.

Kennedy, Christopher (in press). Two Kinds of Subjectivity. In Cécile Meier and Janneke Huitink (Eds.), Subjective Meaning (105-125). De Gruyter.

Kölbel, Max (2004). Faultless Disagreement. Proceedings of the Aristotelian Society, 104(1), 53-73.

Kolodny, Niko (2005). Why Be Rational? Mind, 114(455), 509-563.

Korsgaard, Christine (2008). Self-Constitution. Oxford University Press.

Lasersohn, Peter N. (in press). Subjectivity and Perspective in Truth-Theoretic Semantics. Oxford University Press.

Lasonen-Aarnio, Maria (2015). New Rational Reflection and Internalism about Rationality. In Tamar Szabó Gendler and John Hawthorne (Eds.), Oxford Studies in Epistemology (Vol. 5, 145-171). Oxford University Press.

Lewis, David (1988). Desire as Belief. Mind, 97(387), 323-332.

MacFarlane, John (2014). Assessment Sensitivity. Oxford University Press.

Moss, Sarah (in press). Probabilistic Knowledge. Oxford University Press.

Nussbaum, Martha (2004). Emotions as Judgments of Value and Importance. In Robert C. Solomon (Ed.), Thinking about Feeling (183-198). Oxford University Press.

Parfit, Derek (1984). Reasons and Persons. Clarendon Press.

Prior, A. N. (1976). Thank Goodness That's Over. In Papers in Logic and Ethics (78-84). Duckworth.

Rabinowicz, Wlodek and Toni Rønnow-Rasmussen (2004). The Strike of the Demon. Ethics, 114(3), 391-423.

Reisner, Andrew (2013). Is the Enkratic Principle a Requirement of Rationality? Organon F, 20(4), 437-462.

Richard, Mark (2008). When Truth Gives Out. Oxford University Press.

Rinard, Susanna (in press). No Exception for Belief. Philosophy and Phenomenological Research.

Ross, Jacob and Mark Schroeder (2013). Reversibility or Disagreement. Mind, 122(485), 43-84.

Scanlon, T.M. (1998). What We Owe to Each Other. Harvard University Press.

Schafer, Karl (2011). Faultless Disagreement and Aesthetic Realism. Philosophy and Phenomenological Research, 82(2), 265-286.

Scheffler, Samuel (1994). The Rejection of Consequentialism. Oxford University 
Press.

Schelling, Thomas C. (1960). The Strategy of Conflict. Harvard University Press. Schiffer, Stephen (1976). A Paradox of Desire. American Philosophical Quarterly, 13(3), 195-203.

Sextus Empiricus (1933). Outlines of Pyrrhonism. R. G. Bury (Ed. and Trans). Harvard University Press.

Sinnott-Armstrong, Walter (1984). 'Ought' Conversationally Implies 'Can'. Philosophical Review, 93(2), 249-261.

Spencer, Jack (2016). Disagreement and Attitudinal Relativism. Mind, 125(498), 511-539.

Stephenson, Tamina (2007). Towards a Theory of Subjective Meaning. (Doctoral dissertation). Massachusetts Institute of Technology.

Talbott, W. J. (1991). Two Principles of Bayesian Epistemology. Philosophical Studies, 62(2), 135-150.

Titelbaum, Michael G. (2015). Rationality's Fixed Point (Or: In Defense of Right Reason). In Tamar Gendler and John Hawthorne (Eds.), Oxford Studies in Epistemology (Vol. 5, 253-293). Oxford University Press.

Travis, Charles (2004). The Twilight of Empiricism. Proceedings of the Aristotelian Society, 104(3), 245-270.

Tsai, Jeanne L., Robert W. Levenson, and Kimberly McCoy (2006). Cultural and Temperamental Variation in Emotional Response. Emotion, 6(3), 484-497.

van Fraassen, Bas C. (1984). Belief and the Will. Journal of Philosophy, 81(5), 235256.

van Fraassen, Bas C. (1995). Belief and the Problem of Ulysses and the Sirens. Philosophical Studies, 77(1), 7-37.

Velleman, J. David (2000). The Possibility of Practical Reason. Oxford University Press.

Wedgwood, Ralph (2013). Rational 'Ought' Implies 'Can'. Philosophical Issues, $23(1), 70-92$.

White, Roger (2005). Epistemic Permissiveness. Philosophical Perspectives, 19(1), 445-459.

Wiggins, David (1995). Objective and Subjective in Ethics, with Two Postscripts about Truth. Ratio, 8(3), 243-258.

Williams, Bernard (2011). Ethics and the Limits of Philosophy. Routledge. Originally published 1985 .

Worsnip, Alex (in press). The Conflict of Evidence and Coherence. Philosophy and Phenomenological Research.

Wright, Crispin (1992). Truth and Objectivity. Harvard University Press.

Wright, Crispin (2001). On Being in a Quandary. Mind, 110(437), 46. 